The Revival of Agriculture:

a Constructive Policy for Britain. Prepared by a Committee of the Rural Reconstruction Association. Pp. 138. (London: George Allen and Unwin, Ltd., 1936.) 3s. $6 d$. net.

r.HIS book presents a policy for agricultural reconstruction, with a strong bias towards economic nationalism which the authors, like Signor Mussolini, prefer to call "realism". It gives a clear exposition of the case for national self-sufficiency based on planned agricultural organization, but tends to minimize the disadvantages that might accompany self-sufficiency. Not everyone will agree with the following sweeping statement (p. 125): "It is not arguable that the mere moving of goods backwards and forwards across the seas, though it gives employment to both men and capital, has in itself an economic value". One wonders whether the mere moving of apples from the orchard to the market and thence to the consumer could be dispensed with as easily as shipping, or whether the interposition of water makes all the difference to the necessity for distribution.

The main idea is that our national survival depends on getting more people back to productive work on the land and keeping them there in comfort and security. Few will contend the desirability of this object. The authors realize that it would involve very careful organization of both production and distribution, and full protection of the rural community against price fluctuations, slumps, etc. Much of the security, however, is to be purchased at the cost of the financial and commercial interests that in the past have certainly feathered their nests more effectively than has agriculture, which the authors rightly regard as the foundations of our civilization. It is the misfortune of foundations that they have no place in the sun. What the ultimate consequences to the whole structure of civilization would be of turning the foundations into pinnacles is a question which nobody can yet answer.

G. V. J.

\section{Coordinate Solid Geometry}

Being Chapters I-IX of "An Elementary Treatise on Coordinate Geometry of Three Dimensions". By Prof. Robert J. T. Bell. Pp. xiii $+175+$ xliii. (London : Macmillan and Co., Ltd., 1938.) 7s. $6 d$.

7 HIS book contains, as its text, the first nine chapters of Prof. Bell's well-known "Treatise on Coordinate Geometry of Three Dimensions". It therefore leads up to and completes the treatment of the central surfaces in order to meet the needs of those students who do not desire to study mathematics beyond a pass or general degree standard.

The author has made an interesting and appropriate selection of miscellaneous examples from his larger work and in addition has provided an entirely new set. An appendix has also been added in which alternative and simplified methods to several parts of the original text are given.

The book bears all the excellent features of the "Treatise" and should be of great use to the students for whom it has been prepared.
Silicate Analysis :

a Manual for Geologists and Chemists ; with Chapters on Check Calculations and Geochemical Data. By Dr. A. W. Groves. Pp. xxi +230. (London: Thomas Murby and Co., 1937.) 12s. 6d. net.

THE chemical analysis of silicates is of importance not only in the pure sciences of geology, mineralogy and geochemistry, but also in many branches of technology and industry. The standard works in English on this subject are those of Hillebrand and Washington, and the methods of analysis described in this volume include many given by these workers. These standard methods, however, have been modified where the author's experience has shown such modification to be necessary and, further, other methods are given in detail. Great attention is paid to minutiæ of manipulation, and for ease of consultation the instructions concerning the procedure of the analysis are printed in large type.

After introductory chapters on the equipment of the laboratory, reagents, sampling, and routine operations, the main part of this volume deals fully with the normal methods of silicate analysis. The concluding chapters are devoted to such topics as special methods, analyses for industrial purposes, errors in silicate analysis, and the geochemical distribution of the elements.

This book, which is well produced, provides a detailed guide in silicate analysis for both chemist and geologist.

\section{Modern Optical Projectors :}

a Practical Handbook on the Principles and Construction of Optical Projection Appliances for the Lecture Room, Laboratory and Workshop. By Edgar T. Westbury. Pp. 124. (London: Percival Marshall and Co., Ltd., n.d.) 3s. 6d.

7 HERE is a decided place for this little book in lecture room, laboratory or workshop. As years have gone on, it is surprising what developments have taken place since the 'magic lantern' provided the only means of illustrating a lecture. Yet it remains the prototype of all the more or less elaborate instruments which are in common use to-day for such a purpose.

The information given by the author is severely practical, and covers the whole range of problems likely to arise in the construction and care of projectors. Two points are worthy of special mention. One is the need for absolute darkness during the exhibition of slides. It appears that some five candlepower of stray light on the screen is enough to spoil the effect of five-hundred candle-power of illumination from the lantern. This is common experience, but it is interesting to have figures. The other matter is the value of optical projeetion in the workshop, for example, in the testing of screw threads by casting a shadow of the screw upon the screen at the same time as an enlarged working drawing. Imperfections are readily revealed by this method. The book is well produced and liberally illustrated.

F. I. G. R. 